\title{
Combined transaortic and transapical approach to septal myectomy in patients with complex hypertrophic cardiomyopathy
}

\author{
Dustin Hang, MD, ${ }^{a}$ Hartzell V. Schaff, MD, ${ }^{a}$ Steve R. Ommen, MD, ${ }^{\mathrm{b}}$ Joseph A. Dearani, MD, and \\ Rick A. Nishimura, $\mathrm{MD}^{\mathrm{b}}$
}

\section{ABSTRACT}

Objectives: Residual midventricular obstruction after transaortic myectomy may lead to recurrent symptoms and reoperation in patients with hypertrophic cardiomyopathy and long-segment septal hypertrophy. A combined transaortic and transapical approach to septal myectomy during initial operation allows for the complete relief of subaortic and midventricular gradients and may reduce the risk of poor late functional results.

\begin{abstract}
Methods: We analyzed the early outcomes of 86 patients aged 18 years or more who underwent combined transaortic and transapical septal myectomy for left ventricular outflow tract obstruction due to systolic anterior motion and midventricular obstruction or cavitary obliteration due to apical hypertrophic cardiomyopathy.
\end{abstract}

Results: Midventricular obstruction was present in 59 patients $(68.6 \%)$; 12 patients $(14.0 \%)$ had cavitary obliteration, and 15 patients $(17.4 \%)$ had a combination of both. Overall, median (25th, 75th percentile) prebypass and postbypass directly measured intracavitary gradients were $85 \mathrm{~mm} \mathrm{Hg}(48,125)$ and $4 \mathrm{~mm} \mathrm{Hg}(0,10.8)$, respectively; median predischarge transthoracic left ventricular outflow tract and midventricular gradients were $0 \mathrm{~mm} \mathrm{Hg}(0,0)$ and $0 \mathrm{~mm} \mathrm{Hg}(0,8.5)$. Median crossclamp and perfusion times were 35 minutes $(27,44)$ and 48.5 minutes $(40,64)$. The 30 -day and 1 -year survivals were both $95 \%$, with 2 early deaths. Functional status beyond 30 days postoperatively was available in 42 patients, and 41 patients reported improvement in symptoms and were in New York Heart Association class I/II.

Conclusions: Combined transaortic and transapical septal myectomy is an effective and reasonably safe approach for patients with hypertrophic cardiomyopathy with complex septal hypertrophy. This method may prevent residual midventricular obstruction and permits myectomy to augment diastolic filling and improve left ventricular stroke volume in patients with apical hypertrophic cardiomyopathy. (J Thorac Cardiovasc Surg 2018;155:2096-102)

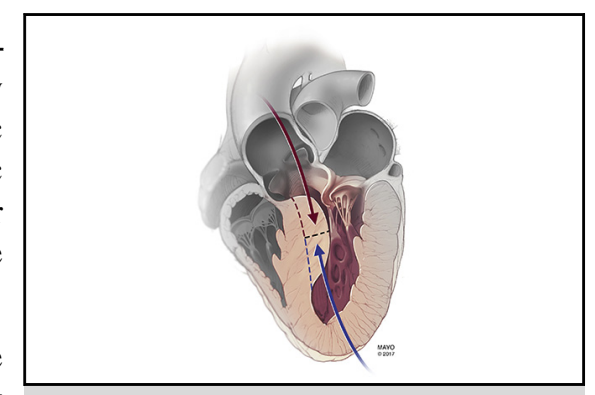

Complex long-segment septal hypertrophy requiring a transaortic and transapical approach.

\section{Central Message}

Combined transaortic and transapical septal myectomy is effective and safe for patients with HCM with complex septal hypertrophy, preventing residual obstruction and augmenting diastolic filling in apical HCM.

\section{Perspective}

Persistent symptoms after septal myectomy may be related to residual LVOT or midventricular gradients due to inadequate length of septal resection or MVO. Many clinicians believe that patients with complex long-segment septal hypertrophy are not candidates for conventional surgery. A combined approach in these patients reduces the risk of residual gradients and is effective and safe.

See Editorial Commentary page 2103.

See Editorial page 2094.

\footnotetext{
From the Departments of ${ }^{\mathrm{a} C a r d i o v a s c u l a r}$ Surgery and ${ }^{\mathrm{b}}$ Cardiovascular Diseases, Mayo Clinic, Rochester, Minn.

This study was supported by the Paul and Ruby Tsai Family.

Read at the 97th Annual Meeting of The American Association for Thoracic Surgery, Boston, Massachusetts, April 29-May 3, 2017.

Institutional Review Board Approval \#16-006761. Approved September 12, 2016.

Received for publication April 29, 2017; revisions received July 7, 2017; accepted for publication Oct 2, 2017; available ahead of print Nov 16, 2017.

Address for reprints: Hartzell V. Schaff, MD, 200 First St SW, Rochester, MN 55905 (E-mail: schaff@mayo.edu). 0022-5223/\$36.00

Copyright @ 2017 Published by Elsevier Inc. on behalf of The American Association for Thoracic Surgery

https://doi.org/10.1016/j.jtcvs.2017.10.054
}

The preferred operation for obstructive hypertrophic cardiomyopathy (HCM) refractory to maximal medical therapy is transaortic septal myectomy. ${ }^{1,2}$ Relief of left ventricular outflow tract (LVOT) gradient improves symptoms in more than $90 \%$ of patients. Persistent

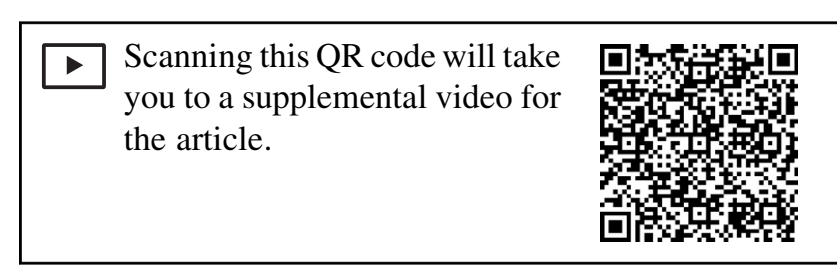




\section{Abbreviations and Acronyms \\ $\mathrm{ECMO}=$ extracorporeal membrane oxygenation \\ $\mathrm{HCM}=$ hypertrophic cardiomyopathy \\ IABP = intra-aortic balloon pump \\ LVOT $=$ left ventricular outflow tract \\ $\mathrm{MVO}=$ midventricular obstruction}

symptoms most often are due to residual LVOT or midcavitary gradients related to inadequate length of septal resection or midventricular obstruction (MVO) (Figure 1). ${ }^{3,4}$

For those patients with MVO as the underlying cause of the residual gradient, a transapical approach for redo septal myectomy is effective, but the optimal strategy would be relief of both subaortic and MVO with combined transaortic and transapical approaches during the initial procedure (Figure 2). Another group of patients who might benefit by extensive myectomy performed through the combined transaortic and transapical incisions are those who present with apical HCM resulting in diastolic heart failure in addition to subaortic obstruction. In these patients, the extensive myectomy is aimed at relieving subaortic obstruction and enlarging the left ventricle cavity to increase stroke volume. The objective of the present study is to detail the early postoperative outcomes in these patients who have undergone extensive myectomy through the combined approach.

\section{MATERIALS AND METHODS \\ Patient Selection and Groups}

From July 1999 to December 2016, a total of 2508 adult patients(aged $\geq 18$ years) underwent septal myectomy for HCM. Of these, $86(3.4 \%)$ underwent combined transaortic and transapical septal myectomy and form the study group. Patients were grouped by indication for the combined approach to myectomy (Figure 3). That is, in addition to subaortic obstruction, the patient had MVO, cavitary obliteration due to apical HCM, or a combination of both. MVO was further divided into that which was known before the institution of cardiopulmonary bypass or that which was discovered after discontinuation of the initial period of bypass; 45 patients $(52.3 \%)$ had MVO known before bypass, 14 patients $(16.3 \%)$ had MVO discovered after discontinuation of bypass, 12 patients $(14.0 \%)$ had cavitary obliteration, and 15 patients $(17.4 \%)$ had a combination of MVO and cavitary obliteration.

Patients were also stratified by the number of bypass runs; 64 patients (74.4\%) underwent a single period of cardiopulmonary bypass, and 22 patients $(25.6 \%)$ required more than 1 bypass period. All patients who did not consent to research were excluded from this surgical series. The study was approved by the Mayo Clinic Institutional Review Board.

\section{Data Collection}

Data on all preoperative, intraoperative, and postoperative variables were obtained from our cardiovascular surgical database or directly from the electronic medical record at the Mayo Clinic in Rochester, Minnesota. Intraoperative intracavitary gradients were recorded using direct needle measurements (see "Surgical Technique"). ${ }^{5}$ Preoperative and predismissal LVOT and midventricular gradients were abstracted from the respective transthoracic echocardiograms.

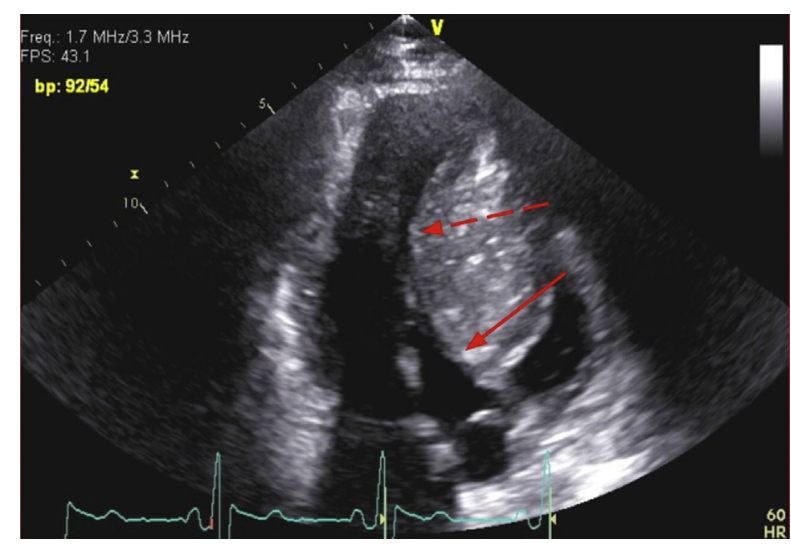

FIGURE 1. Patient with residual subaortic (solid line) and MVO (dashed line) after inadequate resection at another institution during transaortic myectomy as demonstrated by echocardiography.

\section{Statistical Methods}

For bypass groups, comparisons were made with the Pearson's chi-square test of independence or Fisher exact test, as indicated, for categorical variables. Ordinal variables were compared with the

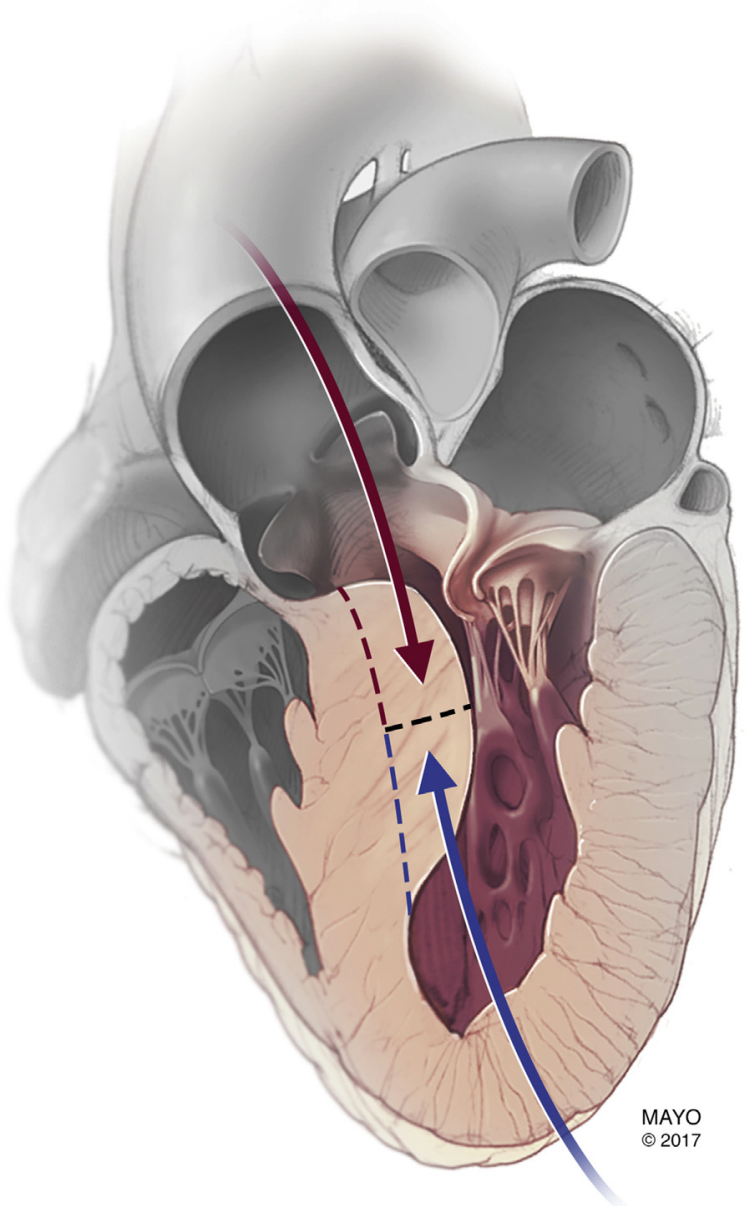

FIGURE 2. Complex long-segment septal hypertrophy requiring both a transaortic approach and a transapical approach. 


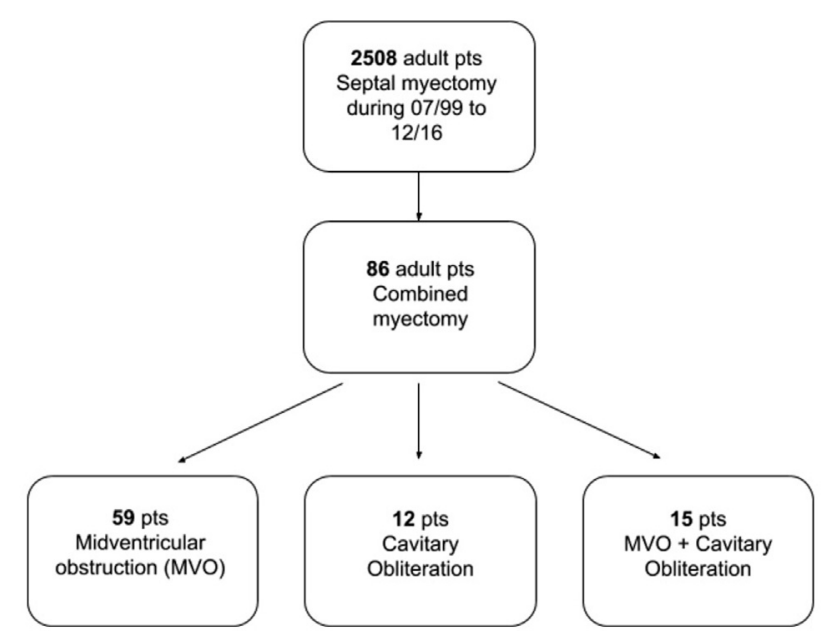

FIGURE 3. Flow chart of patient selection. MVO, Midventricular obstruction.

Cochran-Armitage trend test. Continuous variables were compared between groups using the Wilcoxon rank-sum test. The log-rank test was used for comparisons of survival between groups. A type I error of less than .05 was considered statistically significant. All statistical analyses were conducted using the SAS statistical package (version 9.4, SAS Institute Inc, Cary, NC).

\section{Surgical Technique}

The operative techniques for transaortic and transapical septal myectomy have been described in detail (Video 1). ${ }^{6,7}$ Briefly, after a median sternotomy, direct needle measurement of intracavitary pressure gradients and institution of cardiopulmonary bypass with cardioplegic arrest, the LVOT and subaortic septum are exposed by an oblique aortotomy that extends to the base of the noncoronary sinus. An initial incision in the septum is made at the point of septal-mitral contact (demarcated by a white endocardial scar), beginning just to the right of the nadir of the right aortic sinus. This incision is carried upward initially and then leftward toward the anterior leaflet of the mitral valve, using scissors to complete the excision. A second excision is made more distally

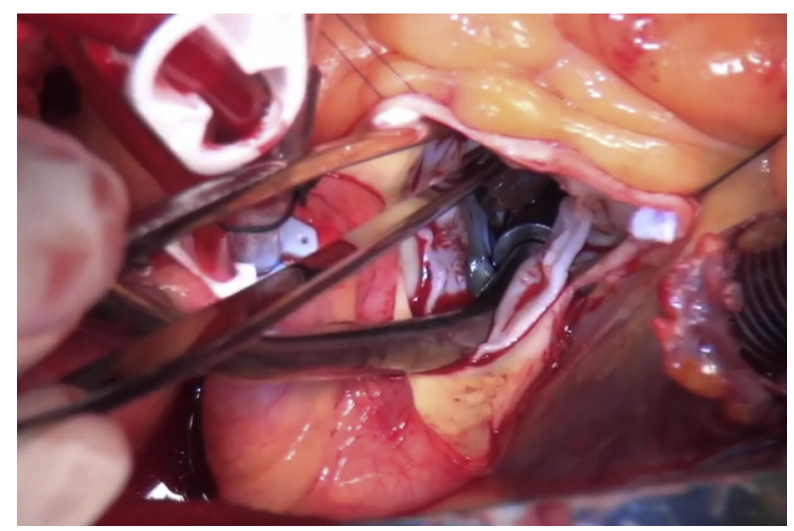

VIDEO 1. Operative video demonstrating the combined transaortic and transapical approach to septal myectomy in patients with complex long-segment septal hypertrophy. Video available at: http://www. jtcvsonline.org/article/S0022-5223(17)32376-0/fulltext. by extending the initial incision further toward the apex of the heart. When present, minor false chords to the septum are divided and markedly hypertrophied papillary muscles are shaved. The aortotomy is closed in 2 layers with 4-0 polypropylene suture.

Attention is then directed toward the apex of the heart, which is delivered anteriorly. A ventriculotomy measuring 5 to $6 \mathrm{~cm}$ is made over the apical dimple, lateral to the left anterior descending artery. The cardiotomy sucker is then used to retract the papillary muscles and chordae away from the septum. The white fibrous endocardial scar is identified, and myectomy of hypertrophied muscle at the level of the scar is performed. Any excess muscle on the ventricular free wall or papillary muscles may be shaved, and any false chords to the septum are divided. The ventriculotomy is closed in 2 layers over Teflon felt strips. Relief of obstruction is confirmed by direct measurement of intracardiac pressures and by transesophageal echocardiography.

\section{RESULTS}

\section{Preoperative Characteristics}

The overall median age of this surgical cohort was 49 (38, $60)$ years. The mean New York Heart Association class was 2.9. There were no differences in baseline preoperative characteristics except for diabetes comparing patients with a single period of cardiopulmonary bypass with those who had an additional procedure during a second period of extracorporeal circulation (Table 1). The median preoperative transthoracic LVOT and midventricular gradients were $80 \mathrm{~mm} \mathrm{Hg}(58,96)$ and $53.5 \mathrm{~mm} \mathrm{Hg}$ $(36,68)$, respectively.

\section{Intraoperative Parameters}

Overall median crossclamp and perfusion times were 35.0 minutes $(27.0,44.0)$ and 48.5 minutes $(40.0,64.0)$, respectively. As expected, perfusion time was longer in patients who had multiple bypass periods compared with those who had combined myectomy during a single bypass period (54.5 vs 44.0 minutes, $P=.007$ ). Crossclamp time also was longer in the multiple bypass group (40.0 vs 32.5 minutes, $P=.091$ ). By direct needle measurements intraoperatively, the maximal intracavitary gradients preoperatively and postoperatively were $85 \mathrm{~mm} \mathrm{Hg}(48$, $125)$ and $4 \mathrm{~mm} \mathrm{Hg}(0,10.8)$, respectively (Table 2). Concomitant mitral valve repair was performed in 7 patients $(8.1 \%)$; no valve replacements were performed. Indications for mitral valve repair included prolapse of the posterior leaflet without flail $(\mathrm{n}=2)$, flail posterior segment with ruptured chordae $(\mathrm{n}=1)$, excessively elongated anterior leaflet $(\mathrm{n}=2)$, and moderate-severe mitral regurgitation of unknown cause discovered after discontinuation of bypass $(\mathrm{n}=2$, intact valve with no systolic anterior motion, no intrinsic mitral valve disease). None of the interventions on the mitral valve were for systolic anterior motion or residual LVOT obstruction.

\section{Postoperative Outcomes}

One patient who had transaortic and transapical myectomy in conjunction with a Maze procedure and 
TABLE 1. Baseline preoperative characteristics

\begin{tabular}{|c|c|c|c|c|c|c|c|c|}
\hline Variable & Total $(\mathbf{n}=86)$ & $\begin{array}{c}\text { MVO before } \\
\text { bypass } \\
(\mathbf{n}=\mathbf{4 5})\end{array}$ & $\begin{array}{c}\text { MVO after } \\
\text { bypass } \\
(\mathrm{n}=14)\end{array}$ & $\begin{array}{c}\text { Cavity } \\
\text { obliteration } \\
(\mathbf{n}=\mathbf{1 2})\end{array}$ & $\begin{array}{c}\text { MVO + cavity } \\
\text { obliteration } \\
(\mathbf{n}=\mathbf{1 5})\end{array}$ & $\begin{array}{l}1 \text { Bypass } \\
(\mathrm{n}=64)\end{array}$ & $\begin{array}{c}>1 \text { Bypass } \\
(n=22)\end{array}$ & $\begin{array}{c}P \\
\text { value }\end{array}$ \\
\hline Surgery year* & $2014(2012,2015)$ & $2014(2014,2015)$ & $2015(2014,2015)$ & $2007(2006,2013)$ & $2013(2008,2015)$ & $2014(2012,2015)$ & $2014(2013,2015)$ & .908 \\
\hline Age at surgery, $y^{*}$ & $49.4(38.9,60.7)$ & $48.9(39.0,60.0)$ & $54.2(47.1,68.7)$ & $51.8(34.3,61.3)$ & $43.8(35.5,57.1)$ & $49.1(37.3,60.4)$ & $53.8(43.5,64.3)$ & .373 \\
\hline Male & $41(47.7 \%)$ & $21(46.7 \%)$ & $8(57.1 \%)$ & $4(33.3 \%)$ & $8(53.3 \%)$ & $29(45.3 \%)$ & $12(54.5 \%)$ & .454 \\
\hline BMI* & $29.4(24.6,33.4)$ & $29.9(24.6,33.1)$ & $29.7(26.0,32.0)$ & $28.7(25.9,31.1)$ & $26.6(23.8,37.2)$ & $29.3(24.6,33.3)$ & $29.7(25.2,33.4)$ & .696 \\
\hline Current smoker & $14(16.3 \%)$ & $4(8.9 \%)$ & $3(21.4 \%)$ & $4(33.3 \%)$ & $3(20.0 \%)$ & $9(14.1 \%)$ & $5(22.7 \%)$ & .342 \\
\hline Diabetes & $13(15.1 \%)$ & $9(20.0 \%)$ & $0(0.0 \%)$ & $2(16.7 \%)$ & $2(13.3 \%)$ & $13(20.3 \%)$ & $0(0.0 \%)$ & .022 \\
\hline Dialysis & $1(1.2 \%)$ & $1(2.2 \%)$ & $0(0.0 \%)$ & $0(0.0 \%)$ & $0(0.0 \%)$ & $1(1.6 \%)$ & $0(0.0 \%)$ & $1.000 \dagger$ \\
\hline Hypertension & $37(43.0 \%)$ & $19(42.2 \%)$ & $5(35.7 \%)$ & $5(41.7 \%)$ & $8(53.3 \%)$ & $27(42.2 \%)$ & $10(45.5 \%)$ & .789 \\
\hline $\begin{array}{l}\text { Cerebrovascular } \\
\text { disease }\end{array}$ & $5(5.8 \%)$ & $2(4.4 \%)$ & $3(21.4 \%)$ & $0(0.0 \%)$ & $0(0.0 \%)$ & $2(3.1 \%)$ & $3(13.6 \%)$ & $.103 \dagger$ \\
\hline NYHA class $\ddagger$ & $2.89[1,4]$ & $2.81[1,4]$ & $2.82[2,3]$ & $3.09[2,4]$ & $3.00[2,4]$ & $2.89[1,4]$ & $2.89[2,4]$ & $.964 \ddagger$ \\
\hline $\begin{array}{l}\text { Recent Atrial } \\
\text { fibrillation/ } \\
\text { atrial flutter }\end{array}$ & $5(6.4 \%)$ & $1(2.4 \%)$ & $2(18.2 \%)$ & $1(9.1 \%)$ & $1(6.7 \%)$ & $3(5.1 \%)$ & $2(10.5 \%)$ & $.590 \dagger$ \\
\hline $\begin{array}{l}\text { Preoperative } \\
\text { beta-blockers }\end{array}$ & $62(72.1 \%)$ & $36(80.0 \%)$ & $8(57.1 \%)$ & $8(66.7 \%)$ & $10(66.7 \%)$ & $48(75.0 \%)$ & $14(63.6 \%)$ & .175 \\
\hline $\begin{array}{l}\text { TTE LVOT } \\
\text { gradient* }\end{array}$ & $80(58,96)$ & $74(55.8,88)$ & $94(82,113)$ & $58(29,89)$ & $80(56,104)$ & $74.5(55,88)$ & $94(82,114)$ & $<.001$ \\
\hline $\begin{array}{l}\text { TTE } \\
\text { midventricular } \\
\text { gradient* }\end{array}$ & $53.5(36,68)$ & $55(37,61)$ & $58(44.5,85.8)$ & $47(28,105)$ & $38(32.5,91.5)$ & $53.5(30.8,69.3)$ & $55(36,69.5)$ & .555 \\
\hline
\end{tabular}

MVO, Midventricular obstruction; BMI, body mass index; NYHA, New York Heart Association; TTE, transthoracic echocardiogram; LVOT, left ventricular outflow tract. *Median (25th, 75th percentiles); Wilcoxon rank-sum test. $\dagger P$ value from Fisher exact test. $\ddagger$ Mean [minimum, maximum]; Cochran-Armitage trend test.

tricuspid valve repair was noted on intraoperative echocardiography to have a small ventricular septal defect. This was repaired successfully through a right ventriculotomy. The patient was the fourth in our series of 86 consecutive patients, and we have not experienced other ventricular septal defects in subsequent cases.

Table 3 summarizes postoperative complications. Of significance, 3 patients $(3.5 \%)$ had strokes. One patient who was recovering satisfactorily had sudden cardiac arrest and required extracorporeal membrane oxygenation (ECMO) support during resuscitation. He remained comatose after this event, and support was withdrawn because of brain death. In another patient, neurologic deficit resolved completely before hospital dismissal. Two patients $(2.3 \%)$ had probable transient ischemic attacks. There were
3 cases $(3.5 \%)$ of complete heart block necessitating the implantation of a permanent pacemaker; 22 patients $(25.6 \%)$ experienced postoperative atrial fibrillation. There were no reoperations for bleeding. The 4 cases of reoperation included institution of ECMO for hemodynamic support after sudden cardiac arrest, exploration for unstable hemodynamics that resolved spontaneously with no identifiable cause, planned delayed sternal closure, and femoral artery thrombectomy due to limb ischemia at the intraaortic balloon pump (IABP) puncture site. Postoperative predismissal transthoracic LVOT and midventricular median gradients were $0 \mathrm{~mm} \mathrm{Hg}(0,0)$ and $0 \mathrm{~mm} \mathrm{Hg}(0$, 8.5), respectively.

Overall 30-day and 1 year survivals were both $95.5 \%$, with 2 early deaths. Functional status beyond 30 days

TABLE 2. Intraoperative variables

\begin{tabular}{|c|c|c|c|c|c|c|c|c|}
\hline Variable & $\begin{array}{c}\text { Total } \\
(\mathbf{n}=\mathbf{8 6})\end{array}$ & $\begin{array}{c}\text { MVO before } \\
\text { bypass } \\
(n=45)\end{array}$ & $\begin{array}{l}\text { MVO after } \\
\text { bypass } \\
(\mathrm{n}=14)\end{array}$ & $\begin{array}{c}\text { Cavity } \\
\text { obliteration } \\
(\mathbf{n}=\mathbf{1 2})\end{array}$ & $\begin{array}{c}\text { MVO + cavity } \\
\text { obliteration } \\
(\mathbf{n}=\mathbf{1 5})\end{array}$ & $\begin{array}{l}1 \text { bypass } \\
(n=64)\end{array}$ & $\begin{array}{c}>1 \text { bypass } \\
(\mathrm{n}=22)\end{array}$ & $\begin{array}{c}P \\
\text { value }\end{array}$ \\
\hline Crossclamp time* & $35.0(27.0,44.0)$ & $32.0(27.0,43.0)$ & $41.0(35.0,46.0)$ & $36.0(30.5,59.0)$ & $34.0(30.0,53.0)$ & $32.5(27.0,43.5)$ & $40.0(33.0,46.0)$ & .091 \\
\hline Perfusion time* & $48.5(40.0,64.0)$ & $46.0(37.0,55.0)$ & $56.5(47.0,64.0)$ & $52.0(41.5,72.5)$ & $43.0(41.0,69.0)$ & $44.0(38.0,61.5)$ & $54.5(48.0,64.0)$ & .007 \\
\hline $\begin{array}{l}\text { Prebypass max } \\
\text { needle intracavitary } \\
\text { gradient }^{*}\end{array}$ & $85(48,125)$ & $88(45,125.5)$ & $99.5(77.5,126.5)$ & $49.5(26,90.3)$ & $65(37,153.75)$ & $67(40,124.5)$ & $96(77.5,126.5)$ & .1082 \\
\hline $\begin{array}{l}\text { Postbypass max needle } \\
\text { intracavitary gradient* }\end{array}$ & $4(0,10.8)$ & $4(0,14)$ & $5(0.5,14.5)$ & $0(0,3)$ & $7(0,9)$ & $4(0,10)$ & $4(0,13.5)$ & .969 \\
\hline
\end{tabular}

MVO, Midventricular obstruction. *Median (25th, 75th percentiles); Wilcoxon rank-sum test. 
TABLE 3. Postoperative outcomes

\begin{tabular}{|c|c|c|c|c|c|c|c|c|}
\hline Variable & $\begin{array}{c}\text { Total } \\
(\mathbf{n}=\mathbf{8 6})\end{array}$ & $\begin{array}{c}\text { MVO before } \\
\text { bypass } \\
(\mathbf{n}=45)\end{array}$ & $\begin{array}{c}\text { MVO after } \\
\text { bypass } \\
(\mathrm{n}=14)\end{array}$ & $\begin{array}{c}\text { Cavity } \\
\text { obliteration } \\
(\mathbf{n}=\mathbf{1 2})\end{array}$ & $\begin{array}{c}\text { MVO + cavity } \\
\text { obliteration } \\
(\mathbf{n}=15)\end{array}$ & $\begin{array}{l}1 \text { Bypass } \\
(n=64)\end{array}$ & $\begin{array}{c}\text { >1 Bypass } \\
(n=22)\end{array}$ & $P$ value \\
\hline IABP & $2(2.3 \%)$ & $0(0.0 \%)$ & $0(0.0 \%)$ & $1(8.3 \%)$ & $1(6.7 \%)$ & $1(1.6 \%)$ & $1(4.5 \%)$ & $.448 *$ \\
\hline ECMO & $1(1.2 \%)$ & $0(0.0 \%)$ & $1(7.1 \%)$ & $0(0.0 \%)$ & $0(0.0 \%)$ & $0(0.0 \%)$ & $1(4.5 \%)$ & $.256^{*}$ \\
\hline Total hours ICU $\dagger$ & $24.5(22.2,48.0)$ & $23.5(22.0,30.0)$ & $23.2(22.2,41.6)$ & $25.5(22.5,67.5)$ & $49.6(24.5,97.5)$ & $24.5(22.4,46.8)$ & $23.4(22.0,52.0)$ & .791 \\
\hline $\begin{array}{c}\text { Total hours ventilated } \\
\text { postoperatively } \dagger\end{array}$ & $5.0(4.0,7.0)$ & $5.0(3.7,6.0)$ & $5.0(4.0,10.0)$ & $4.6(3.9,12.5)$ & $7.7(5.0,18.2)$ & $5.0(3.7,6.6)$ & $5.0(4.0,11.0)$ & .181 \\
\hline Reoperation within $30 \mathrm{~d}$ & $4(4.7 \%)$ & $1(2.2 \%)$ & $1(7.1 \%)$ & $1(8.3 \%)$ & $1(6.7 \%)$ & $2(3.1 \%)$ & $2(9.1 \%)$ & $.269^{*}$ \\
\hline Superficial sternal infection & $1(1.2 \%)$ & $1(2.2 \%)$ & $0(0.0 \%)$ & $0(0.0 \%)$ & $0(0.0 \%)$ & $1(1.6 \%)$ & $0(0.0 \%)$ & $1.000 *$ \\
\hline Deep sternal infection & $0(0.0 \%)$ & $0(0.0 \%)$ & $0(0.0 \%)$ & $0(0.0 \%)$ & $0(0.0 \%)$ & $0(0.0 \%)$ & $0(0.0 \%)$ & \\
\hline Septicemia & $1(1.2 \%)$ & $0(0.0 \%)$ & $0(0.0 \%)$ & $1(8.3 \%)$ & $0(0.0 \%)$ & $1(1.6 \%)$ & $0(0.0 \%)$ & $1.000 *$ \\
\hline Stroke & $3(3.5 \%)$ & $1(2.2 \%)$ & $2(14.3 \%)$ & $0(0.0 \%)$ & $0(0.0 \%)$ & $1(1.6 \%)$ & $2(9.1 \%)$ & $.160 \%$ \\
\hline Transient ischemic attack & $2(2.3 \%)$ & $2(4.4 \%)$ & $0(0.0 \%)$ & $0(0.0 \%)$ & $0(0.0 \%)$ & $2(3.1 \%)$ & $0(0.0 \%)$ & $1.000 *$ \\
\hline Prolonged ventilation & $6(7.0 \%)$ & $1(2.2 \%)$ & $1(7.1 \%)$ & $2(16.7 \%)$ & $2(13.3 \%)$ & $3(4.7 \%)$ & $3(13.6 \%)$ & $.172 *$ \\
\hline Pneumonia & $2(2.3 \%)$ & $1(2.2 \%)$ & $0(0.0 \%)$ & $0(0.0 \%)$ & $1(6.7 \%)$ & $1(1.6 \%)$ & $1(4.5 \%)$ & $.448 *$ \\
\hline Renal failure & $2(2.3 \%)$ & $0(0.0 \%)$ & $0(0.0 \%)$ & $2(16.7 \%)$ & $0(0.0 \%)$ & $2(3.1 \%)$ & $0(0.0 \%)$ & $1.000 *$ \\
\hline Complete heart block & $3(3.5 \%)$ & $1(2.2 \%)$ & $0(0.0 \%)$ & $0(0.0 \%)$ & $2(13.3 \%)$ & $2(3.1 \%)$ & $1(4.5 \%)$ & $1.000 *$ \\
\hline Atrial fibrillation & $22(25.6 \%)$ & $13(28.9 \%)$ & $6(42.9 \%)$ & $0(0.0 \%)$ & $3(20.0 \%)$ & $16(25.0 \%)$ & $6(27.3 \%)$ & .833 \\
\hline TTE LVOT gradient ${ }^{\dagger}$ & $0(0,0)$ & $0(0,0)$ & $0(0,1)$ & $0(0,0)$ & $0(0,0)$ & $0(0,0)$ & $0(0,0)$ & .97 \\
\hline TTE midventricular gradient $\dagger$ & $0(0,8.5)$ & $0(0,13)$ & $0(0,8.3)$ & $0(0,0)$ & $0(0,22.3)$ & $0(0,12)$ & $0(0,8.3)$ & .649 \\
\hline Survival $\ddagger$ & & & & & & & & .381 \\
\hline $30 \mathrm{~d}$ & $95.5 \%(2)$ & $100.0 \%(0)$ & $75.0 \%(1)$ & $88.9 \%(1)$ & $100.0 \%(0)$ & $98.0 \%(1)$ & $87.5 \%(1)$ & \\
\hline $1 \mathrm{y}$ & $95.5 \%(2)$ & $100.0 \%(0)$ & $75.0 \%(1)$ & $88.9 \%(1)$ & $100.0 \%(0)$ & $98.0 \%(1)$ & $87.5 \%(1)$ & \\
\hline
\end{tabular}

$M V O$, Midventricular obstruction; IABP, intra-aortic balloon pump; $E C M O$, extracorporeal membrane oxygenation; $I C U$, intensive care unit; TTE, transthoracic echocardiogram; LVOT, left ventricular outflow tract. * $P$ value from Fisher exact test. $\dagger$ Median (25th, 75 th percentiles); Wilcoxon rank sum test. $\ddagger$ Kaplan-Meier estimate, $\%$ (number of deaths), of cumulative mortality; log-rank test.

postoperatively was available in 42 patients; median followup time was 17 months $(5.5,29.3)$. Forty-one patients $(97.6 \%)$ reported improvement in symptoms and were in New York Heart Association class I or II.

\section{DISCUSSION}

The combined transaortic and transapical approach has been used at the Mayo Clinic over the last 18 years in patients with complex long-segment septal hypertrophy to relieve subaortic and MVO, as well as to prevent cavitary obliteration and enlarge the left ventricular chamber in patients with apical HCM (Figures 4 and 5). The steps in this operation for septal myectomy have been described by others. ${ }^{6,8,9}$

There is a spectrum of morphologic subgroups of HCM, and some patients with LVOT obstruction appear to have both MVO and small left ventricular chambers contributing to diastolic heart failure. Indeed, untreated MVO is associated with reduced survival and increased risk of ventricular arrhythmias. ${ }^{10}$ Also, patients undergoing reoperation who have persistent midventricular gradients due to inadequate resection exhibit debilitating symptoms. ${ }^{3,4}$

As is true for patients with isolated subaortic obstruction, a complete excision of obstructing muscle is essential in abolishing pressure gradients in patients with MVO. In our experience, an apical myectomy in combination with a transaortic myectomy allows for complete resection during the initial operation in those patients with complex long-segment septal hypertrophy, thereby preventing the recurrence of gradients and symptoms that might require reintervention. In recent years, we have identified patients preoperatively with marked distal septal hypertrophy who appear to be at high risk of residual MVO. These patients often have obliteration of the left ventricular cavity due to apical HCM (Figure 4), and in those patients we now proceed with transapical septal myectomy in conjunction with transaortic myectomy.

As documented in this clinical review, combined transaortic and transapical myectomy was effective in abolishing subaortic and midventricular gradients; median predismissal transthoracic LVOT and midventricular gradients were $0 \mathrm{~mm} \mathrm{Hg}(0,0)$ and $0 \mathrm{~mm} \mathrm{Hg}(0,8.5)$, respectively. In this series, overall 30 -day and 1 -year survivals were $95.5 \%$. The 2 deaths were due to postoperative heart failure leading to multiorgan failure after satisfactory initial recovery. Among survivors with follow-up data past 30 days (49\%), symptom relief was gratifying with functional improvement in $97.6 \%$ of patients.

The risk of neurologic complications after the combined approach was greater than we have observed in our series of 

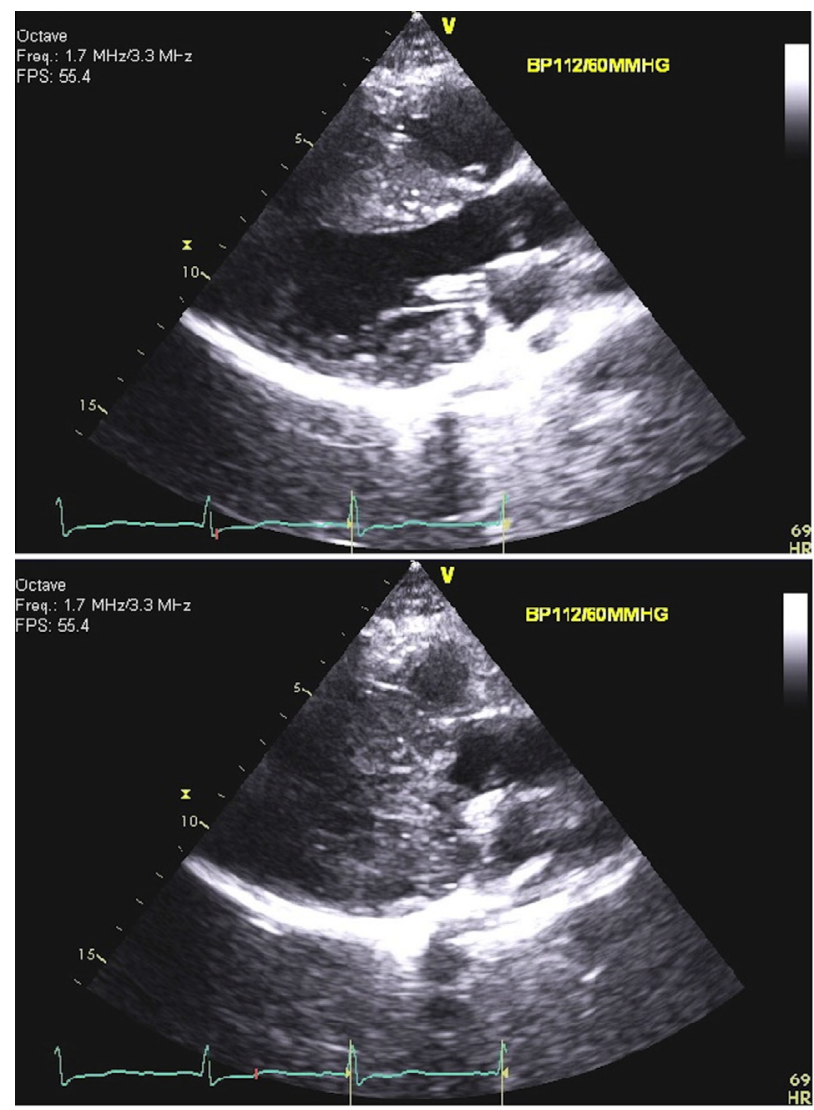

FIGURE 4. Patient who presented with both subaortic and MVO, as well as cavitary obliteration. Top: Parasternal long-axis view at the beginning of systole. Bottom: Parasternal long-axis view at the end of systole.

isolated transaortic myectomies (ie, $<1 \%$ ), but it was comparable to stroke rates reported for transcatheter aortic valve replacement and mitral valve surgery. ${ }^{1-15}$ In 1 patient, stroke occurred after sudden cardiac arrest and institution of ECMO for hemodynamic support. Multiorgan failure developed in this patient, and the patient remained comatose until death. In a second patient, the source of embolization to the right middle cerebral artery was a fragment of myocardium that was identified on retrieval via urgent endovascular recanalization therapy; the patient recovered except for a mild residual facial droop after rehabilitation. ${ }^{16}$ The remaining patient with embolic stroke recovered to baseline status by hospital dismissal. A greater risk of neurologic complications might be anticipated in patients who are at higher risk of operation and require a more extensive myectomy for relief of obstruction.

Other postoperative outcomes were comparable to those previously reported for septal myectomy, including renal failure in 2 patients $(2.3 \%)$ and complete heart block in 3 patients $(3.5 \%) .{ }^{17,18}$ Median mechanical ventilation hours, 5 $(4,7)$, and intensive care unit hours, 24.5 (22.2, 48.0), are consistent with fast-track postoperative cardiac care.
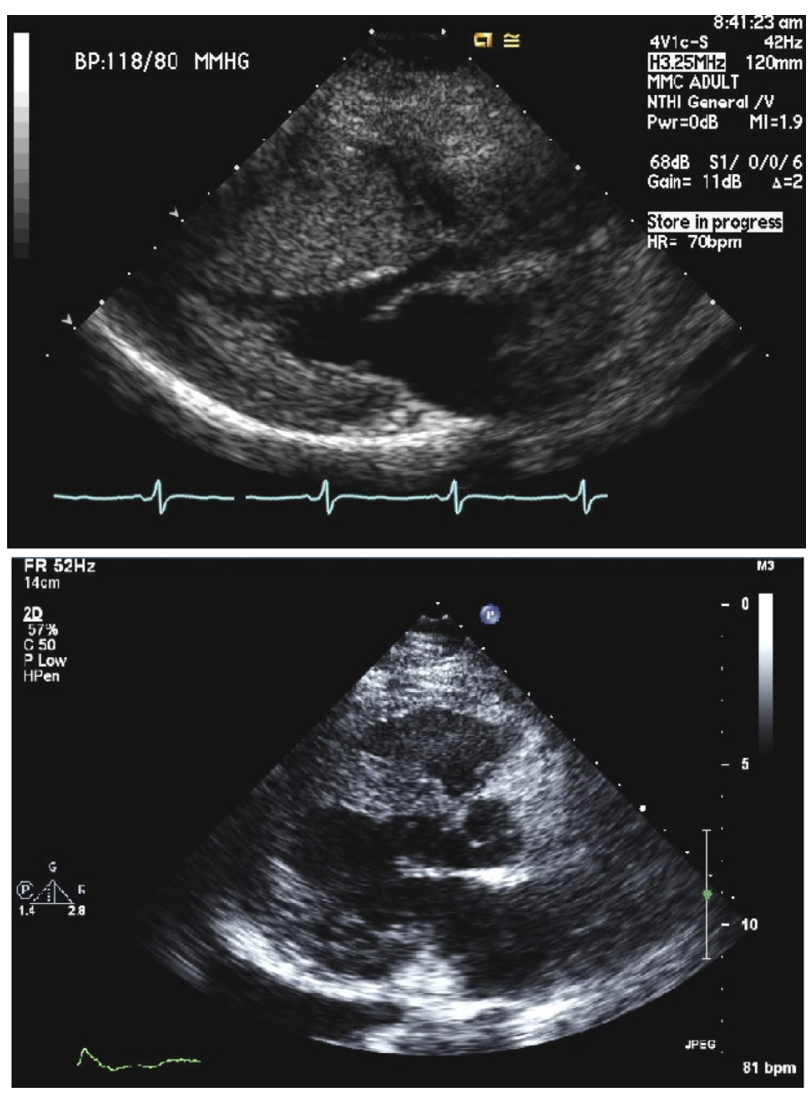

FIGURE 5. Patient with subaortic obstruction and apical HCM resulting in cavitary obliteration. Top: Parasternal long-axis view on preoperative transthoracic echocardiography during early diastole. Bottom: Parasternal long-axis view on postoperative transthoracic echocardiography during early diastole after combined myectomy.

There were no statistical differences in survival between patients with a single bypass run and patients with multiple bypass runs. This supports similar results reported by Hong and colleagues. ${ }^{19}$ In addition, multiple bypass periods do not seem to significantly increase crossclamp time. The need for additional bypass runs should not inhibit surgeons from proceeding with additional transaortic or transapical myectomies for those patients in whom additional obstruction is confirmed intraoperatively. Indeed, MVO was not identified until after discontinuation of bypass in 14 patients. Of the 22 patients who had multiple bypass periods, the second bypass run was for additional transapical and transaortic myectomy in 17 and 5 patients, respectively.

There are several case reports of using alcohol septal ablation in cases of HCM with MVO or apical hypertrophy. ${ }^{20-22}$ It logically follows that one may attempt to use alcohol septal ablation for relief of both subaortic and MVO. However, there is remaining concern over the effectiveness of alcohol septal ablation in the midventricular region. ${ }^{23}$ The complex anatomy of the 
papillary muscles and their contribution to MVO may prove to be an obstacle for relief of obstruction by injection of ethanol into septal perforators, thereby only targeting the septum. We believe our combined approach allows for a more complete and durable treatment for these complex cases.

\section{Study Limitations}

The primary aim of this study is descriptive in nature. As such, our surgical series of 86 patients may not provide adequate power for robust statistical comparisons between the groups as defined in this study. We elected not to conduct statistical comparisons between indication groups. Information on functional outcome is limited; the focus of the present study was on early and short-term outcomes; therefore, further study with longer follow-up times is necessary. However, it is important to note that vital status is known in all patients.

\section{CONCLUSIONS}

A combined transaortic and transapical approach to septal myectomy is effective in abolishing subaortic and midventricular gradients, as well as enlarging the left ventricle when cavitary obliteration due to apical HCM is present. It is a reasonably safe procedure in those patients with HCM with complex long-segment septal hypertrophy. Using this approach during the initial operation may prevent the need for reoperation due to residual midventricular gradients.

\section{Conflict of Interest Statement}

Authors have nothing to disclose with regard to commercial support.

\section{References}

1. American College of Cardiology Foundation/American Heart Association Task Force on Practice, American Association for Thoracic Surgery, American Society of Echocardiography, et al. 2011 ACCF/AHA guideline for the diagnosis and treatment of hypertrophic cardiomyopathy: a report of the American College of Cardiology Foundation/American Heart Association Task Force on Practice Guidelines. J Thorac Cardiovasc Surg. 2011;142:e153-203.

2. Maron BJ, Maron MS. Hypertrophic cardiomyopathy. Lancet. 2013;381:242-55.

3. Minakata K, Dearani JA, Schaff HV, O'Leary PW, Ommen SR, Danielson GK. Mechanisms for recurrent left ventricular outflow tract obstruction after septal myectomy for obstructive hypertrophic cardiomyopathy. Ann Thorac Surg. 2005;80:851-6.

4. Cho YH, Quintana E, Schaff HV, Nishimura RA, Dearani JA, Abel MD, et al. Residual and recurrent gradients after septal myectomy for hypertrophic cardiomyopathy-mechanisms of obstruction and outcomes of reoperation. J Thorac Cardiovasc Surg. 2014;148:909-16.

5. Ashikhmina EA, Schaff HV, Ommen SR, Dearani JA, Nishimura RA, Abel MD. Intraoperative direct measurement of left ventricular outflow tract gradients to guide surgical myectomy for hypertrophic cardiomyopathy. J Thorac Cardiovasc Surg. 2011;142:53-9.

6. Said SM, Schaff HV, Abel MD, Dearani JA. Transapical approach for apical myectomy and relief of midventricular obstruction in hypertrophic cardiomyopathy. J Card Surg. 2012;27:443-8.

7. Schaff HV, Said SM. Transaortic extended septal myectomy for hypertrophic cardiomyopathy. Oper Tech Thorac Cardiovasc Surg. 2012;17:238-50.

8. Kunkala MR, Schaff HV, Nishimura RA, Abel MD, Sorajja P, Dearani JA, et al. Transapical approach to myectomy for midventricular obstruction in hypertrophic cardiomyopathy. Ann Thorac Surg. 2013;96:564-70.

9. Schaff HV, Brown ML, Dearani JA, Abel MD, Ommen SR, Sorajja P, et al. Apical myectomy: a new surgical technique for management of severely symptomatic patients with apical hypertrophic cardiomyopathy. J Thorac Cardiovasc Surg. 2010;139:634-40.

10. Minami Y, Kajimoto K, Terajima Y, Yashiro B, Okayama D, Haruki S, et al. Clinical implications of midventricular obstruction in patients with hypertrophic cardiomyopathy. J Am Coll Cardiol. 2011;57:2346-55.

11. Nagueh SF, Ommen SR, Lakkis NM, Killip D, Zoghbi WA, Schaff HV, et al. Comparison of ethanol septal reduction therapy with surgical myectomy for the treatment of hypertrophic obstructive cardiomyopathy. J Am Coll Cardiol. 2001;38:1701-6.

12. Ommen SR, Maron BJ, Olivotto I, Maron MS, Cecchi F, Betocchi S, et al. Long-term effects of surgical septal myectomy on survival in patients with obstructive hypertrophic cardiomyopathy. J Am Coll Cardiol. 2005;46: 470-6.

13. Mastoris I, Schoos MM, Dangas GD, Mehran R. Stroke after transcatheter aortic valve replacement: incidence, risk factors, prognosis, and preventive strategies. Clin Cardiol. 2014;37:756-64.

14. Leon MB, Smith CR, Mack MJ, Makkar RR, Svensson LG, Kodali SK, et al. Transcatheter or surgical aortic-valve replacement in intermediate-risk patients. N Engl J Med. 2016;374:1609-20.

15. Udesh R, Mehta A, Gleason TG, Wechsler L, Thirumala PD. Perioperative strokes and early outcomes in mitral valve surgery: a nationwide analysis. J Cardiothorac Vasc Anesth. 2017;31:529-36.

16. Murphy ME, Lanzino G, Raghunathan A, Schaff H, Fugate JE. Unique cause of right hemispheric syndrome: embolism of myocardium after open septal myectomy. Neuroradiol J. 2016;29:110-4.

17. Panaich SS, Badheka AO, Chothani A, Mehta K, Patel NJ, Deshmukh A, et al. Results of ventricular septal myectomy and hypertrophic cardiomyopathy (from Nationwide Inpatient Sample [1998-2010]). Am J Cardiol. 2014;114:1390-5.

18. Kim LK, Swaminathan RV, Looser P, Minutello RM, Wong SC, Bergman G, et al. Hospital volume outcomes after septal myectomy and alcohol septal ablation for treatment of obstructive hypertrophic cardiomyopathy: US Nationwide Inpatient Database, 2003-2011. JAMA Cardiol. 2016;1:324-32.

19. Hong JH, Schaff HV, Nishimura RA, Abel MD, Dearani JA, Li Z, et al. Mitral regurgitation in patients with hypertrophic obstructive cardiomyopathy: implications for concomitant valve procedures. J Am Coll Cardiol. 2016;68: 1497-504.

20. Tengiz I, Ercan E, Alioglu E, Turk UO. Percutaneous septal ablation for left mid-ventricular obstructive hypertrophic cardiomyopathy: a case report. $B M C$ Cardiovasc Disord. 2006;6:15.

21. Seggewiss H, Faber L. Percutaneous septal ablation for hypertrophic cardiomyopathy and mid-ventricular obstruction. Eur J Echocardiogr. 2000;1: 277-80.

22. Angelini P, Uribe C, Monge J, Escobar JM, Hernandez-Vila E. Apical hypertrophic cardiomyopathy: preliminary attempt at palliation with use of subselective alcohol ablation. Tex Heart Inst J. 2012;39:750-5.

23. Veselka J. Twenty years of alcohol septal ablation document more than a history of a single interventional procedure. Cor Vasa. 2015;57:e16-27.

Key Words: hypertrophic cardiomyopathy, surgery/incisions/exposure/techniques 